\title{
Hypocenter distribution of the main- and aftershocks of the 2005 Off Miyagi Prefecture earthquake located by ocean bottom seismographic data
}

\author{
Ryota Hino $^{1}$, Yojiro Yamamoto ${ }^{1}$, Asako Kuwano ${ }^{1}$, Minoru Nishino $^{1}$, Toshihiko Kanazawa ${ }^{2}$, Tomoaki Yamada ${ }^{2}$, \\ Kazuo Nakahigashi ${ }^{2}$, Kimihiro Mochizuki ${ }^{2}$, Masanao Shinohara ${ }^{2}$, Kouetsu Minato ${ }^{3}$, Gen Aoki ${ }^{3}$, \\ Nariaki Okawara ${ }^{4}$, Masayuki Tanaka ${ }^{4}$, Masao Abe ${ }^{4}$, Eiichiro Araki ${ }^{5}$, \\ Shuichi Kodaira ${ }^{5}$, Gou Fujie ${ }^{5}$, and Yoshiyuki Kaneda ${ }^{5}$ \\ ${ }^{1}$ Graduate School of Science, Tohoku University, Sendai 980-8578, Japan \\ ${ }^{2}$ Earthquake Research Institute, The University of Tokyo, Tokyo 113-0032, Japan \\ ${ }^{3}$ Sendai District Meteorological Observatory, Japan Meteorological Agency, Sendai 983-0842, Japan \\ ${ }^{4}$ Seismological and Volcanological Department, Japan Meteorological Agency, Tokyo 100-8122, Japan \\ ${ }^{5}$ Japan Agency for Marine-Earth Science and Technology, Yokosuka 237-0061, Japan
}

(Received November 30, 2005; Revised February 1, 2006; Accepted April 29, 2006; Online published February 2, 2007)

\begin{abstract}
The preliminary hypocenter distribution of the 2005 Off Miyagi Prefecture earthquake and its aftershocks is estimated using data from five ocean bottom and six onshore seismic stations located around the rupture area of the earthquake. The epicenter of the mainshock is relocated at $38.17^{\circ} \mathrm{N}, 142.18^{\circ} \mathrm{E}$, and the focal depth is estimated to be $37.5 \mathrm{~km}$. The aftershocks surrounding the mainshock hypocenter form several clusters that are concentrated along a distinct landward dipping plane corresponding to the plate boundary imaged by the previous seismic experiment. The strike and dip angles of the plane agree well with those of the focal mechanism solution of the mainshock. The size of the plane is about $20 \times 25 \mathrm{~km}^{2}$ in the strike and dip directions, which is similar to that of the large coseismic slip area. The up-dip end of the planar distribution of the aftershocks corresponds to the bending point of the subducting oceanic plate, suggesting that the geometry of the plate boundary affects the spatial extent of the asperity of the 2005 earthquake.
\end{abstract}

Key words: Off Miyagi Prefecture earthquake, interplate seismicity, Ocean bottom seismographs.

\section{Introduction}

The landward slope area of the Japan Trench subduction zone is characterized by active interplate seismicity, and large earthquakes with magnitudes of 7 and higher have occurred repeatedly. Yamanaka and Kikuchi (2004) have shown that these large interplate earthquakes are repeating ruptures of asperities - areas of large coseismic slip that are locked during interseismic periods along the surface of the subducting Pacific plate. In the middle part of the subduction zone, the $M=7.5$ class earthquakes off Miyagi Prefecture are known to occur with a recurrence interval of about 40 years. The most recent event of this earthquake sequence occurred in 1978, 27 years ago, and the Japanese government announced that the probability of the occurrence of such a $M=7.5$ class earthquake within the next 10 years is about 50\% (HERP, 2003). On August 16 2005, an earthquake of $M=7.2$ occurred off Miyagi Prefecture. The focal mechanism solution of the earthquake was of a thrust fault type (e.g. F-Net; NIED, 2005), indicating that this event was an interplate earthquake, but its seismic moment was $5.4 \times 10^{19} \mathrm{Nm}$ (e.g. F-Net; NIED, 2005), which was significantly smaller than that of the earthquake forecasted to occur. Okada et al. (2005) proposed that the 2005 earthquake was a re-rupturing of one of the asperities of the preceding

Copyright (c) The Society of Geomagnetism and Earth, Planetary and Space Sciences (SGEPSS); The Seismological Society of Japan; The Volcanological Society of Japan; The Geodetic Society of Japan; The Japanese Society for Planetary Sciences; TERRAPUB.
1978 earthquake. If this were the case, the rupture area of the 2005 is an asperity that ruptures repeatedly in the consecutive earthquakes, and it is very important to reveal its exact location to understand the characteristics of these asperities. In order to clarify the spatial and temporal distribution of the seismicity around off the Miyagi Prefecture area, we have made a series of ocean bottom seismographic observations since 2002 by repeated deployment and retrieval of pop-up type ocean bottom seismographs (OBSs). At the time this earthquake occurred, 15 OBSs were in operation. Following the occurrence of the $M=7.2$ earthquake, we decided to retrieve five OBSs deployed around the epicenter to determine the precise hypocenter locations of the mainshock and subsequent aftershocks as soon as possible. This paper describes our preliminary results on the hypocenter determination using only the data recorded on these five OBSs, which were retrieved 12 days after the mainshock. Our aim was to show the location and geometry of the fault ruptured by the 2005 earthquake. Some of the OBSs recording the 2005 earthquake are still in operation and will be retrieved in May 2006. We will then present our final results using all the OBS data.

\section{Data and Analyses}

The OBSs used in this study are of a free-fall/pop-up type developed by Kanazawa and Shiobara (1994) and are equipped with a three-component geophone. The seismic waveform data are continuously recorded onto hard disk 


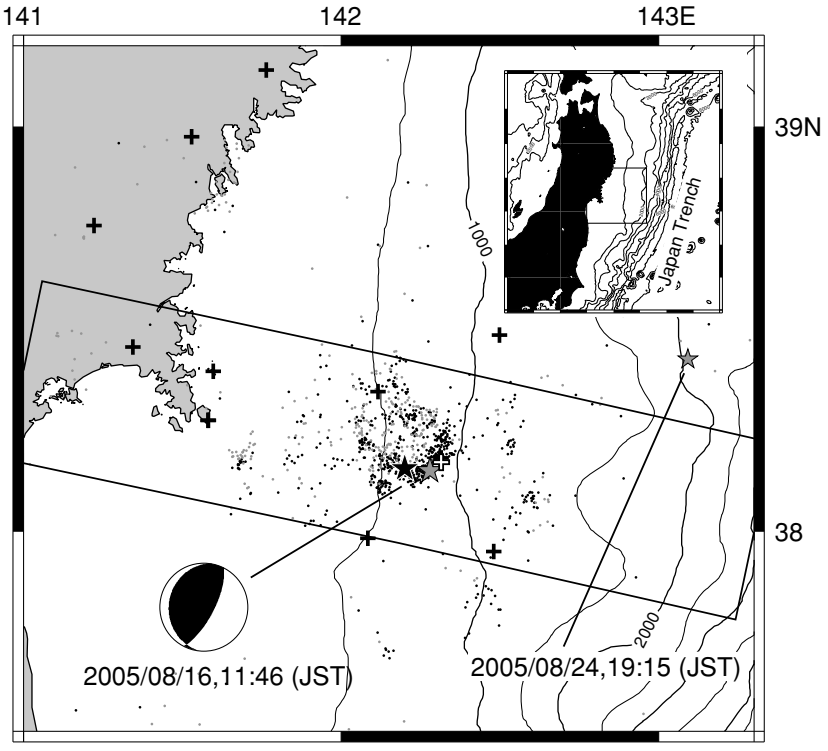

Fig. 1. Epicenter distribution of the mainshock and aftershocks of the 2005 Off Miyagi Prefecture earthquake. Epicenters of the aftershocks that occurred until August 24 are plotted. Gray stars represent the epicenters of the mainshock, and an $M=6.3$ earthquake occurred on Aug. 24, as determined by Japan Meteorological Agency (JMA). The black star is the mainshock epicenter located by the conventional hypocenter determination of this study. Dots are aftershock epicenters (gray: JMA; black: this study). Crosses are the locations of the seismic stations: five offshore and six onshore. The focal mechanism solution by F-net NIED (2005) is also shown. Focal depth distribution of the hypocenters in the rectangle is shown in Fig. 3. Contours are isobaths in meters

drives after A/D conversion (20 bit/128 Hz) The accuracy of the timing is kept within $0.05 \mathrm{~s}$ by using a high-precision quartz oscillator calibrated to a GPS clock before and after the observation. The OBSs were deployed in July 2005 by R/V Kofu-maru and were retrieved by R/V Yokosuka at end of August, 12 days after the occurrence of the 2005 Off Miyagi Prefecture earthquake; as such, they provide continuous waveform records from July 13 to August 28. The locations of the OBS stations are shown in Fig. 1 and Table 1, and they were estimated by acoustic triangulation measurements.

In this study, we relocated the hypocenter of the mainshock occurred at 11:46 on Aug. 16 and those of aftershocks that took place up to August 24, the date of occurrence of another large (M 6.3) earthquake near the Japan Trench. We did not relocate hypocenters of this M 6.3 earthquake and its aftershocks in this study because it was well outside our OBS network $\left(38.44^{\circ} \mathrm{N}, 143.09^{\circ} \mathrm{E}\right.$, according to the Japan Meteorological Agency catalogue). We picked the $P$ and $S$ waves arrival times of the target events from the OBS records and also from records of six onshore stations (Fig. 1 and Table 1) nearby the aftershock region, operated by Tohoku University and JMA.

Using the picked arrival time data, hypocenters were calculated assuming one-dimensional (1-D) seismic velocity structure models shown in Fig. 2. We referred to the $V p$ structure model estimated by the marine seismic exploration conducted in this area (Ito et al., 2005), and a $V p / V s$ ratio of 1.73 is assumed. Absolute arrival time data were first inverted for hypocenter locations; this was followed by
Table 1. Locations of the seismic stations. $P S-P$ times were used for travel time delay due to the sedimentary layer.

\begin{tabular}{ccccc}
\hline Station & Latitude & Longitude & Altitude (m) & $P S$ - $P$ time (s) \\
\hline S01 & $38^{\circ} 20.853^{\prime}$ & $142^{\circ} 06.941^{\prime}$ & -519 & 1.4 \\
S02 & $37^{\circ} 58.967^{\prime}$ & $142^{\circ} 05.045^{\prime}$ & -537 & 1.9 \\
S03 & $38^{\circ} 10.952^{\prime}$ & $142^{\circ} 18.950^{\prime}$ & -971 & 2.5 \\
S04 & $38^{\circ} 29.276^{\prime}$ & $142^{\circ} 29.969^{\prime}$ & -1104 & 2.5 \\
S05 & $37^{\circ} 56.963^{\prime}$ & $142^{\circ} 28.889^{\prime}$ & -1068 & 1.9 \\
KN5 & $38^{\circ} 16.578^{\prime}$ & $141^{\circ} 34.956^{\prime}$ & -435 & - \\
EN3 & $38^{\circ} 23.874^{\prime}$ & $141^{\circ} 35.856^{\prime}$ & -265 & - \\
TKY & $38^{\circ} 45.486^{\prime}$ & $141^{\circ} 13.308^{\prime}$ & 26 & - \\
KSN & $38^{\circ} 58.590^{\prime}$ & $141^{\circ} 31.806^{\prime}$ & 280 & - \\
SN3 & $39^{\circ} 08.406^{\prime}$ & $141^{\circ} 45.816^{\prime}$ & 105 & - \\
OURI & $38^{\circ} 27.438^{\prime}$ & $141^{\circ} 20.718^{\prime}$ & 40 & - \\
\hline
\end{tabular}

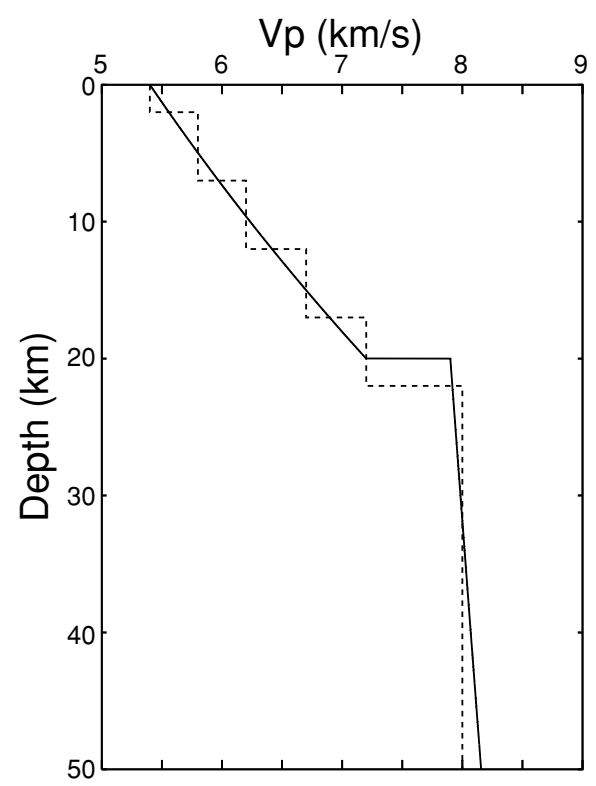

Fig. 2. $V p$ structure models for the conventional hypocenter determination using absolute travel time data (solid line) and for the double-difference location method (dashed line). In both of the hypocenter determinations, $V p / V s$ is assumed to be 1.73 .

application of the double-difference (DD) method (Waldhouser and Ellsworth, 2000) to the calculated hypocenters to obtain the final hypocenter distribution.

The arrival time data at the OBS stations was subjected to corrections to account for the travel time delays due to the sedimentary layer with very low $V p$ and $V s$ covering the ocean floor. The delay times for the $P$ - and $S$-waves can be estimated from the $V p, V s$ and the thickness of the layer. The $V p$ and $V s$ for this layer are assumed to be constant and 2.0 and $0.57 \mathrm{~km} / \mathrm{s}$, respectively, and variations in the sediment thickness for each of the OBS stations are estimated from the differences in arrival times between the $P$-wave and the $S$-waves converted from the direct $P$-wave at the basement of the sedimentary layer (see Hino et al., 2000). Observed $P S-P$ times for five OBS stations are tabulated in Table 1.

The hypocenter coordinates calculated from the arrival time data thus corrected assuming the 1-D velocity structure were used as the initial locations of the hypocenters 

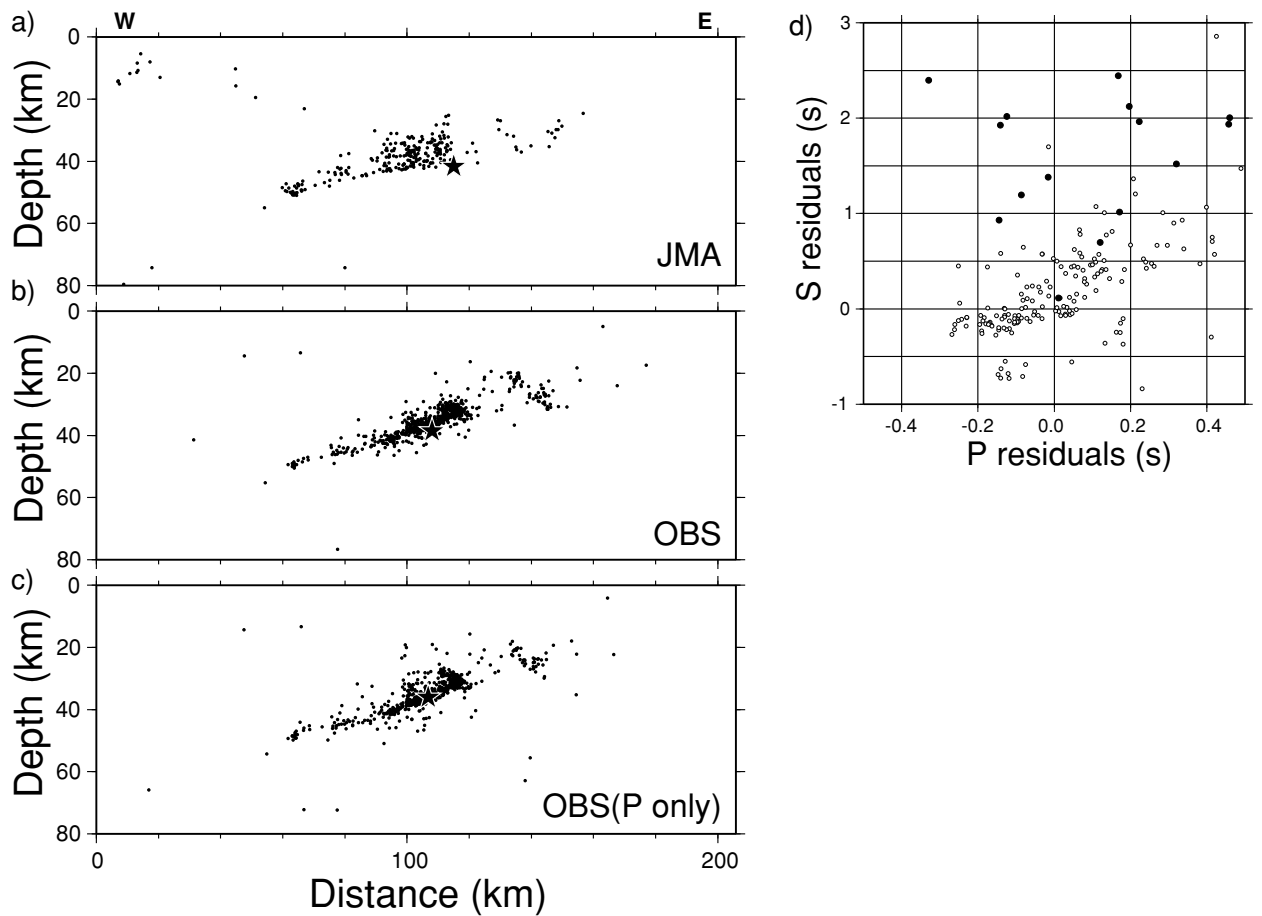
travel time residuals for $P$ - and $S$-waves (d). (a) Focal depth distribution determined by JMA. Star and dots are for the mainshock and aftershocks, respectively. (b) Focal depth distribution determined by this study. Arrival times of both $P$ - and $S$-waves are used. (c) Focal depth distribution using only $P$-wave arrival time data. (d) Relation between travel time residuals for $P$ - and $S$-waves at each of the onshore seismic stations. Solid symbols are for the mainshock and open symbols are for aftershocks whose epicenters are located within $2 \mathrm{~km}$ from the mainshock.

in the double difference (DD) location analysis. Double differences of the travel times are measured for the event pairs with separations of less than $15 \mathrm{~km}$. We did not apply any waveform cross correlation measurements to obtain the travel time differences; these were instead obtained from the arrival time data picked up by the operators. Both $P$ and $S$-wave data were used in the DD hypocenter relocation.

\section{Results}

In Fig. 1, the epicenters determined by the ordinary hypocenter locations using absolute travel times are shown. Hypocenters with root mean square (rms) travel time residuals of less than $0.3 \mathrm{~s}$ are plotted. The relocated epicenters show more compact distribution than those from the JMA catalogue. Although no systematic differences are recognized between the relocated and the catalogue aftershock distributions, the epicenter of the mainshock is relocated at $38.17^{\circ} \mathrm{N}, 142.18^{\circ} \mathrm{E}$ to about $8 \mathrm{~km}$ west of the epicenter reported by JMA. Although the catalogue mainshock epicenter is located at the eastern edge of the aftershock distribution, the relocated one is in the middle of one of the aftershock clusters.

The focal depth distributions according to the JMA catalogue and relocated by using the OBS data are shown in Fig. 3(a) and (b), respectively. It is evident that the resolution of focal depths is considerably improved by using the OBS data. Most of the relocated hypocenters are concentrated along a landward dipping plane corresponding to the fault plane of the mainshock - the plate boundary. The hypocenter of the mainshock by JMA is determined below the landward dipping aftershock plane (Fig. 3(a)) and remains below the aftershock distribution even compared to the OBS data (Fig. 3(b)). However, the focal depth of the mainshock is almost the same as those of the surrounding aftershocks when we use only $P$-wave arrival time data (Fig. 3(c)), indicating that the $S$-wave arrival time data account for the deeper hypocenter of the mainshock.

Figure 3(d) shows travel time residuals of $P$ - and $S$ waves for the mainshock and the aftershocks whose locations are within a distance of $2 \mathrm{~km}$ from the mainshock. The residuals are calculated using the hypocenter locations determined by the $P$-wave arrival time data only. The $S$ residuals are less than $0.5 \mathrm{~s}$ for most of the aftershocks, even for the hypocenters determined without $S$-wave data. Notwithstanding this, the residuals for the mainshock exceed $1 \mathrm{~s}$ at many seismic stations and amount to more than $2 \mathrm{~s}$ for several stations. For this reason, we judged that the hypocenter locations determined using the $P$-wave data alone is more reliable in terms of the mainshock and subsequently excluded the $S$-wave arrival times of the mainshock from our data set.

Figure 4 shows the hypocenter distribution of the mainshock and the aftershocks of the 2005 Off Miyagi Prefecture earthquake. Gray dots are the results of the ordinary hypocenter determination. Using these hypocenters as the initial locations, we applied the DD location method to obtain black dots in the figure. The DD relocation analysis did not substantially moved the hypocenter location of the mainshock. The focal depth of the mainshock is estimated to be $37.5 \mathrm{~km}$.

The epicenters of the mainshock and a number of the 

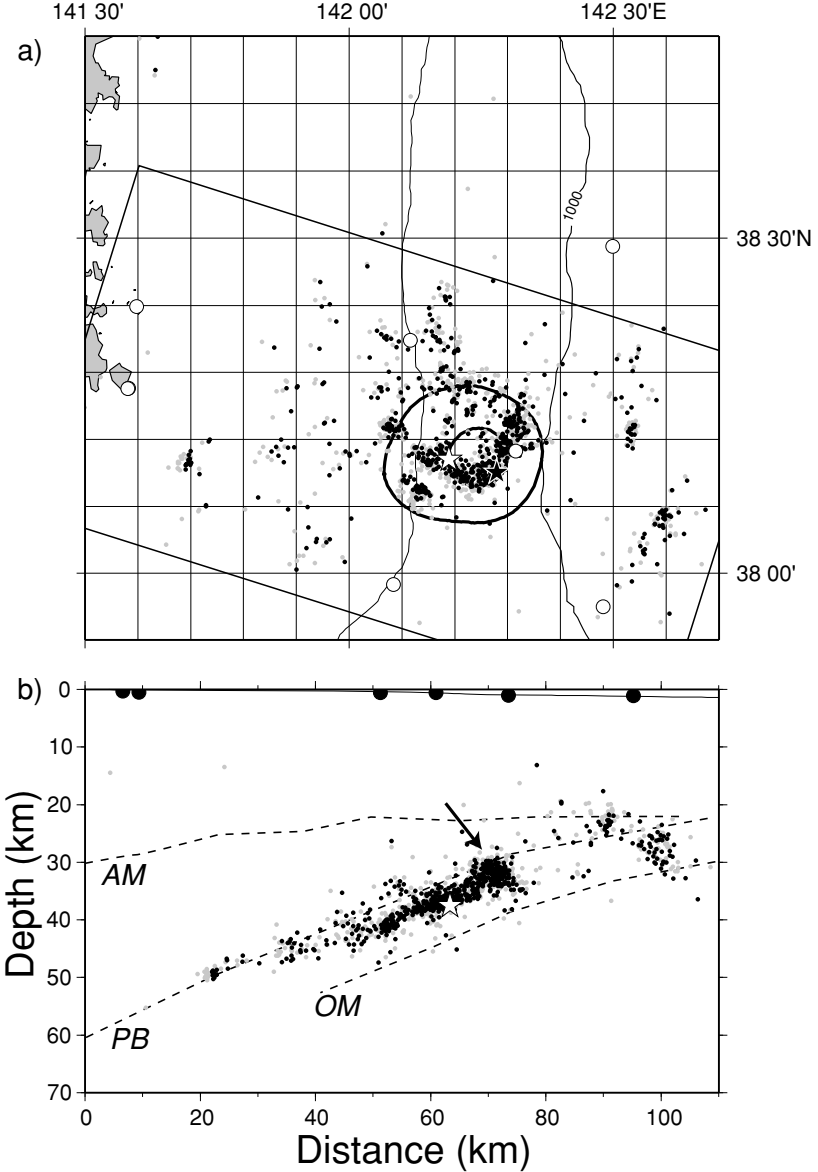

Fig. 4. Relocated hypocenter distribution of the mainshock and aftershocks of the 2005 Off Miyagi earthquake. Gray and black dots are determined by the conventional inversion and the DD location method, respectively. The white star is the location of the mainshock hypocenter. (a) Epicenter distribution. Open circles are the locations of seismic stations. The black star indicates the epicenter of the mainshock according to the JMA catalogue. Thick contours show coseismic slip distribution by Yaginuma et al. (2005) with an interval of $0.3 \mathrm{~m}$. (b) Focal depth distribution of the earthquakes in the rectangle shown in (a). Solid circles are the locations of the seismic stations projected onto the cross section. Dashed lines are major layer boundaries estimated by the seismic experiment (Ito et al., 2005). AM, Arc's Moho; PB, plate boundary; OM, oceanic crust's Moho. An arrow points to the position of the NNS-SSW trending arm of the L-shape cluster of the aftershocks marking the up-dip end of the rupture area.

aftershocks form an 'L'-shaped cluster (denoted the "main cluster" in subsequent text). Two arms of the ' $L$ ' are orthogonal to each other and have almost the same length, about $15 \mathrm{~km}$. The mainshock is included in the WNW-ESE trending arm. The hypocenters belonging to the main cluster and its surrounding area span about 20 - and $25-\mathrm{km}$ areas in the strike and dip directions, and concentrate well to a landward dipping plane. The plane has a strike of $197^{\circ}$ and a dip of $24^{\circ}$, and its depth ranges from 30 to $45 \mathrm{~km}$. It is interesting that the directions of the two arms nearly correspond to the strike and dip direction of the landward dipping plane.

The activity of the aftershocks outside of the planar structure zone is quite sparse, and few evident clusters can be seen. It is therefore difficult to image the overall shape of the aftershock distribution due to the sparseness of the data. The hypocenters in the western part seem to be along the extension of the plane of the main cluster of aftershocks down to a depth of about $50 \mathrm{~km}$, although the distribution of focal depth is more diffuse than that found in the main cluster. To the east of the main cluster, there are two active clusters. The hypocenters in these clusters are more scattered in terms of focal depths and do not seem to form a planar structure.

\section{Discussion}

The L-shaped main cluster and its surrounding aftershocks show a distinct planar structure, and the dip and strike of this plane coincide well with the focal mechanism solutions. For example, the dip and strike of the F-net solution are $22^{\circ}$ and $197^{\circ}$, respectively. In Fig. 4, the coseismic slip of the 2005 Off Miyagi Prefecture earthquake determined by teleseismic waveform data (Yaginuma et al., 2005 ) and the spatial extent of the rupture area is almost the same as the size of the plane-shaped aftershock distribution. These comparisons suggest that the aftershock distribution obtained by this study reflects the exact location of the asperity of the 2005 earthquake.

The planar structure of the aftershocks is terminated by the NNE-SSW trending arm of the L-shaped main cluster. The hypocenters east of the cluster show a diffuse distribution of focal depth, suggesting that the NNE-SSW arm marks the up-dip limit of the rupture area of the mainshock and that the aftershocks in the eastern part may occur off the plane of the mainshock rupture, possibly within the subducting oceanic crust. In Fig. 4, the rupture area estimated from the analysis of the teleseismic data extends more to the east than the actual location of the NNE-SSW trending arm, and this seems to be in contradiction to our interpretation. However, the coseismic slip distribution can be shifted eastward compared to our aftershock distribution because Yaginuma et al. (2005) assumed that that the rupture started at the hypocenter location determined by JMA, which is about $8 \mathrm{~km}$ east of the relocated hypocenter. If they took the relocated hypocenter as the point of the rupture initiation, the eastward limit of the coseismic rupture should coincide with the location of the NNS-SSW lineation of the aftershocks It is often reported that the aftershock activity tends to be inactive in the asperity region, where the amount of coseismic slip is large (see Hino et al., 2000; Scholz, 2002). In the case of the 2005 earthquake, the aftershocks around the mainshock epicenter concentrate into small clusters, and several areas of low seismicity occur in the areas of the asperities ruptured by the mainshock. For example, the ENE-WSW trending arm of the L-shaped aftershock distribution seems to split the asperity imaged by the teleseismic waveform inversion into the northern and southern portions, each of which corresponds to the aseismic zone surrounded by the aftershock clusters. The slip distribution of the 2005 earthquake might be more complex than the waveform inversion result.

Okada et al. (2005) reanalyzed the land seismic network data to compare the aftershock distribution of the 2005 earthquake with that of the 1978 earthquake and also with the background seismicity pattern. They pointed out that the regions of active seismicity show little temporal variation, which implies that the seismic coupling is con- 
trolled by persistent characteristics, such as structural heterogeneities along or in the vicinity of the plate boundary. The locations of the aftershock clusters can be interpreted as the weakly coupled zones of the plate boundary.

The plane formed by the main cluster events nearly coincides with the plate boundary determined by the seismic exploration. Although the aftershock plane is slightly deeper than that of the plate boundary imaged by the seismic reflection signals, the dip angle is in good agreement. The focal depths determined here are heavily dependent on the assumed $V p / V s$ values used in estimating the corrections at each station or the travel time calculations. The aftershock distribution will move upward without changing its overall shape, if we assume a larger $V p / V s$ value than those used in this study. For example, focal depths decrease by about $1 \mathrm{~km}$ if we assume 1.80 as the $V p / V s$ in the upper layer in the structure model shown in Fig. 2. Although no reliable $V s$ structure has been revealed beneath the landward slope of the Japan trench, large $V p / V s$ values $(>2.0)$ have been estimated for the upper part of the crust in the offshore regions around Japan (Obana et al., 2001). The estimation of the plate boundary depth by the seismic experiment may also contain systematic error. Therefore, it is difficult to discuss with any degree of certainty whether the depth difference between the planar distribution of the aftershocks and the plate boundary imaged by the wide-angle reflection data is significant.

Ito et al. (2005) pointed out that there are two bending points where the dip angle of the plate boundary changes suddenly and that the eastern edges of the rupture areas of the 1978 and 1981 Off Miyagi earthquakes correspond to these bending points. The eastern limit of the planar aftershock distribution, which we interpret as the eastern limit of the rupture area of the 2005 earthquake, corresponds to the location of the bending point of the plate boundary, as does that of the 1978 earthquake. As reviewed by Scholtz (2002), irregularities of fault geometry, such as bends, can be impediments to rupture propagation. The rupture propagation of the 2005 earthquake may be terminated by the bending of the fault plane located about $10 \mathrm{~km}$ up-dip of the hypocenter. King and Nablek (1985) explained that the termination of the rupture propagation can be caused by a reduction of the stress at the tip of a growing fault due to a spreading of the deformation over a broad zone around the bending point. It is interesting that the aftershock plane is a little thicker at the up-dip end (indicated by an arrow in Fig. 4(b)) than the deeper part. The seismicity of the NNS-SSW trending arm of the L-shaped cluster may be pronounced because of intraplate seismicity that is activated as the result of the rupture termination process.

\section{Conclusions}

In this study we relocate the hypocenters of the mainshock and aftershocks of the Off Miyagi Prefecture earthquake (M=7.2) that occurred on August 16, 2005 using data obtained by five OBSs and six onshore seismic stations.

By using data recorded at the OBSs, we were able to considerably improve the spatial resolution of the hypocenter distribution. The preliminary hypocenter of the mainshock is relocated to $38.17^{\circ} \mathrm{N}, 142.18^{\circ} \mathrm{E}$, and the focal depth is estimated to be $37.5 \mathrm{~km}$, about $8 \mathrm{~km}$ landward and $5 \mathrm{~km}$ upward of the JMA published hypocenter. The result of a hypocenter determination using absolute arrival times of $P$ and $S$-waves, assuming a $1-\mathrm{D}$ seismic structure model, was that the mainshock hypocenter seems to be mislocated if the $S$-wave arrival time data are included in the inversion.

Using the hypocenters determined by the conventional calculations described above as initial locations, we employed the DD location method to obtain an aftershock distribution that was as detailed as possible. Most of the aftershocks concentrate around the mainshock hypocenter and form several clusters. The most active cluster contains the mainshock hypocenter and is in the shape of the letter L. These aftershock clusters form a sharply defined landward dipping plane with 15 - and $25-\mathrm{km}$ spans in the strike and dip directions, respectively. The strike and dip of the plane are $197^{\circ}$ and $24^{\circ}$, almost the same as those of the focal mechanism solution of the mainshock. The spatial extent of the plane of concentrating aftershocks may indicate the location of the rupture area of the mainshock. The aftershocks on the periphery of the rupture area show a more diffuse distribution, perhaps due to off-plane aftershock activity.

The location of the plane of the aftershock distribution corresponds to an area within 3-4 km of the plate boundary imaged by the previous wide-angle seismic reflection experiment. The imaged plate boundary changes its dip at a depth of approximately $30 \mathrm{~km}$, and the location of this change seems to agree to the eastward limit of the in-plane aftershock activity. This correlation suggests that the shape of the plate boundary may control the spatial extent of the rupture of the 2005 earthquake.

Acknowledgments. We would like to thank the officers and crew of R/V Kofu-maru (Hakodate Marine Observatory, Japan Meteorological Agency) and R/V Yokosuka (Japan Agency for MarineEarth Science and Technology) for their skilful support. We are also grateful to Mr. T. Yagi, S. Hashimoto, I. Terada and T. Koizumi for their help in the OBS observations. We would like to thank Dr. K. McIntosh and an anonymous reviewer for their valuable comments. This study is partly supported by the Special Coordination Funds for Promotion of Science and Technology (MEXT, Japan).

\section{References}

F-net, NIED, NIED CMT solutions, http://www.fnet.bosai.go.jp, 2005. The Headquaters for Earthquake Research Promotion (HERP), MEXT, Japan, Long-term evaluation of the Miyagi-Oki earthquakes, 2003 (in Japanese).

Hino, R, S. Ito, H. Shiobara, H. Shimamura, T. Sato, T. Kanazawa, J. Kasahara, and A. Hasegawa, Aftershock distribution of the 1994 Sanriku-oki earthquake (Mw 7.7) revealed by ocean bottom seismographic observation, J. Geophys. Res., 105, 21697-21710, 2000.

Ito A., G. Fujie, S. Miura, S. Kodaira, R. Hino, and Y. Kaneda, Bending of the subducting oceanic plate and its implication for rupture propagation of large interplate earthquakes off Miyagi, Japan, in the Japan trench subduction zone, Geophys. Res. Lett., 32, doi:10.1029/2004GL022307, 2005 .

Kanazawa, T. and H. Shiobara, Newly developed ocean-bottom seismometer, Abstr. Japan Earth Planet. Sci. Joint Meet., I11-P82, 1994 (in Japanese).

King, G. and J. Nablek, Role of fault bends in the initiation and termination of earthquake rupture, Science, 228, 984-987, 1985.

Obana, K., S. Kodaira, K. Mochizuki and M. Shinohara, Micro-seismicity around the seaward updip limit of the 1946 Nankai earthquake dislocation area, Geophys. Res. Lett., 28, 2333-2336, 2001.

Okada, T. T. Yaginuma, N. Umino, T. Kono, T. Matsuzawa, S. Kota, and A. 
Hasegawa, The 2005 M7.2 Miyagi-Oki Earthquake, NE Japan: Possible re-rupturing of asperities that caused the previous M7.4 earthquake, Geophys. Res. Lett., 32, doi:10.1029/2005GL024613 2005.

Scholz, C. H., The Mechanics of Earthquakes and Faulting, 471 pp, Cambridge Univ. Press, Cambridge, 2002.

Waldhauser, F. and W. L. Ellsworth, A double-difference earthquake location algorithm: method and application to the Northern Hayward fault, Bull. Seism. Soc. Am., 90, 1353-1368, 2000.

Yaginuma, T., T. Okada, N. Umino, and A. Hasegawa, Asperity of the 2005 off Miyagi earthquake (M7.2) estimated by waveform inversion,
Program Abstr. Seismol. Soc. Jpn., PM16, 2005 (in Japanese). Yamanaka, Y. and M. Kikuchi, Asperity map along the subduction zone in northeastern Japan inferred from regional seismic data, J. Geophys. Res., 109, doi:10.1029/2003JB002683, 2004.

R. Hino (e-mail: hino@aob.geophys.tohoku.ac.jp), Y. Yamamoto, A. Kuwano, M. Nishino, T. Kanazawa, T. Yamada, K. Nakahigashi, K. Mochizuki, M. Shinohara, K. Minato, G. Aoki, N. Okawara, M. Tanaka, M. Abe, E. Araki, S. Kodaira, G. Fujie, and Y. Kaneda 